\title{
Development of genetic models for estimation of racing performances in German thoroughbreds
}

\author{
Dedicated to Prof. Dr. habil. Peter Glodek on the occasion of his $70^{\text {th }}$ birthday
}

\begin{abstract}
The objective of this study was to develop new statistical models for genetic estimation of racing performances in German thoroughbreds. Analysed performance traits were "square root of rank at finish", "square root of distance to first placed horse in a race" and "log of earnings". These traits were found to be influenced by the carried weight, which was determined by the horse's earlier performance. Therefore, new traits were developed based on random regression models, which were independent from the carried weights. Heritabilities were first estimated for these created traits "new rank at finish" $\left(\mathrm{h}^{2}=0.101\right)$ and "new distance to first placed horse in a race" $\left(\mathrm{h}^{2}=0.142\right)$ by using two univariate animal models. When considering a linear regression of carried weights as fixed effect in the statistical model, heritabilities for "square root of rank at finish" $\left(h^{2}=0.086\right)$ and "square root of distance to first placed horse in a race" $\left(\mathrm{h}^{2}=0.124\right)$ decreased. Breeding values of "new rank at finish" and "new distance to first placed horse in a race" were compared with breeding values of "square root of rank at finish" and "square root of distance to first placed horse in a race", in which carried weight was considered as fixed regression in the model. These two different models were compared by two criteria. Breeding values were overestimated for low performing thoroughbreds and underestimated for high performing horses when considering a linear regression of carried weights as fixed effect in the model. Statistical models considering new created traits ("new rank at finish" and "new distance to first placed horse in a race") which were independent of carried weights, showed better suitability for genetic estimation. Due to high genetic correlation with other traits and showing highest genetic variance a univariate animal model for the trait "new distance to first placed horse in a race” was recommended for genetic estimation.
\end{abstract}

Key Words: Genetic parameters, Random Regression Model, Thoroughbreds, Racing performance, Carried weights

\section{Zusammenfassung}

Titel der Arbeit: Entwicklung genetischer Modelle zur Schätzung von Rennleistungen bei deutschen Vollblütern

Das Ziel dieser Studie war die Entwicklung von statistischen Modellen zur genetischen Schätzung von Rennleistungen in der deutschen Vollblutzucht. Die Rennleistungsmerkmale „Wurzel der Platzziffer“, „Wurzel des Abstandes zum ersten Platz in einem Rennen“ und „log Gewinnsumme“ wurden analysiert. Das zu tragende Gewicht der Vollblüter in Rennen, das auf vorher erbrachten Leistungsbeobachtungen basiert, beeinflusste die genannten Leistungsmerkmale. Deshalb wurden auf der Grundlage von Random-Regression-Modellen neue Merkmale entwickelt, die unabhängig von den getragenen Gewichten waren. Die Heritabilitäten für diese neu erstellten Merkmale „neue Platzziffer“ $\left(\mathrm{h}^{2}=0,101\right)$ und „neuer Abstand zum ersten Platz in einem Rennen“ $\left(\mathrm{h}^{2}=\right.$ 0,142) wurden mit zwei univariaten Tiermodellen geschätzt. Die Einbeziehung einer „linearen Regression der getragenen Gewichte“ als fixen Effekt im statistischen Modell führte zu einer Abnahme der Heritabilitäten für die Merkmale „Wurzel der Platzziffer“ $\left(\mathrm{h}^{2}=0,086\right)$ und „Wurzel des Abstandes zum ersten Platz in einem Rennen“ $\left(h^{2}=0,124\right)$. Die Zuchtwerte für die Merkmale „neue Platzziffer“ und „neuer Abstand zum ersten Platz in einem Rennen“ wurden mit den Zuchtwerten für die „Wurzel der Platzziffer“ und der „Wurzel des Abstandes zum ersten Platz in einem Rennen“ verglichen. Die beiden letztgenannten Merkmale wurden mit einem Modell geschätzt, dass das getragene Gewicht als fixe Regression berücksichtigte. Der Vergleich der verschiedenen Modelle erfolgte anhand von zwei Kriterien. Die Berücksichtigung einer fixen Regression des getragenen 
Gewichtes im statistischen Modell ergab überschätzte Zuchtwerte für leistungsschwache Vollblüter und unterschätzte Zuchtwerte für leistungsstarke Vollblüter. Die statistischen Modelle für die neu erstellten Merkmale („neue Platzziffer“ und „,neuer Abstand zum ersten Platz in einem Rennen“), die unabhängig von dem getragenem Gewicht waren, wiesen eine bessere Eignung für die Zuchtwertschätzung auf. Ein univariates Tiermodell für das Merkmal „,neuer Abstand zum ersten Platz in einem Rennen“ zeigte aufgrund der hohen genetischen Korrelationen zu anderen Merkmalen und der hohen genetischen Varianz die beste Eignung für die genetische Schätzung.

Schlüsselwörter: Genetische Parameter, Random-Regression-Modell, Vollblüter, Rennleistung, getragenes Gewicht

\section{Introduction}

The breeding goal in German thoroughbreds is a fast, highly competitive and sound horse with a correct exterior. Selection decisions are implemented by using the end-ofyear general handicap weights of raced horses, that are estimated by professional compilers. This criterion for selection is entirely based on the horse's own performance and expresses its racing merit as a weight in $\mathrm{kg}$. Non-starting thoroughbreds do not receive a general handicap. In German trotter breed, selection is performed by using breeding values for racing performance traits estimated at present with a multiple trait BLUP animal model (ROEHE et al., 2001). Breeding value evaluation procedures were previously also developed for German thoroughbred breed. The BLUP methodology was first introduced in genetic evaluation about one decade ago. Initially, a BLUP sire model was used for the trait general handicap weights (SCHULZE-SCHLEPPINGHOFF et al., 1987). PREISINGER et al. (1993) applied a BLUP animal model for the traits rank at finish and earnings. The last developed genetic evaluation based also on a BLUP animal model and considered only the trait rank at finish (JAITNER et al., 1994; UPHAUS and SCHMUTZ, 1998). In this genetic model the carried weight which bias real performance ability of horses, was included as fixed effect.

In trotters, the trait racing time per km is very important for selection (ROEHE et al, 2001; BUGISLAUS et al., 2004). Individual race results of thoroughbred competitions contain only racing times for the first placed horses. Otherwise for thoroughbreds the variable stewards' decision is available in the data. This variable gives additional information on the distance between sequentially ranked thoroughbreds in the finish of races. It was never analysed genetically. Therefore, it is necessary to examine, whether the use of stewards' decision as additional trait will result in further improvement of the accuracy of estimated breeding values. In order to avoid possible bias, it is also required to analyse the optimal consideration of carried weights in races.

The objectives of this study were (1) creation of new performance traits independent from carried weights, (2) genetic analyses of the traits rank at finish, stewards' decision and earnings and (3) development of a new breeding value evaluation system.

2.

Material and methods

2.1 Creation of new performance traits independent from carried weights

The total data set for the analyses of performance traits consisted of 33,223 performance observations from 2,507 thoroughbreds starting in flat races in the years 2002 and 2003. Only thoroughbreds which performed in more than six flat races were included in this data set. It was assumed that raced horses were unrelated. The analysed traits were "rank at finish" and "distance to the first placed horse in a race". 
In order to achieve a reasonable approximation to the normal distribution, rank at finish was transformed by its square root. This transformed trait was subtracted of a constant with the value 5. So that positive breeding values resemble desired genetic merit. A constant of 5 was used in order to get no values lower than zero for transformed trait rank at finish.

The trait distance to the first placed horse was obtained by summation of sequential stewards' decisions. It was expressed in horse lengths. The variable stewards' decision in the data described the distance between two sequentially placed thoroughbreds in a race when they passed the finish. A square root transformation of the trait distance to the first placed horse was necessary, to receive a reasonable approximation to the normal distribution. This transformed trait was subtracted of a constant with the value 10. The value 10 was utilised because transformed trait distance to the first placed horse in a race should not receive a lower value than 0 . In the following context, "distance to the first placed horse in a race" is abbreviated as "distance to first rank".

Performance observations in the data showed not the real performance potential of horses because competing thoroughbreds had to carry different weights in individual races. These carried weights expressed the racing merit of horses in comparison with all starting thoroughbreds. Weights were allocated for each race by professional compilers. For genetic evaluation, unbiased performance traits are desirable. Therefore, two new traits independent from carried weights were created. For this reason, coefficients of phenotypical performance traits on carried weights were estimated within each individual thoroughbred by using random regression models. In order to estimate a coefficient for each horse, at least six observations per thoroughbred had to be considered in the data. Two different univariate statistical models for the traits transformed rank at finish and transformed distance to first rank were used for estimations of coefficients on carried weights. These two models included only a random animal effect and a residual effect. The space variable was the carried weight. A first order polynomial on carried weights for the animal effect was applied in both estimations. The program VCE5 (KOVAC et al., 2002) was utilised for evaluations of coefficients of transformed rank at finish as well as of transformed distance to first rank on carried weights. The most frequent coefficients from both evaluations over all animals were used for creation of new performance traits. The following equation shows the creation of the trait new rank at finish.

New rank at finish $=\left(\left(5-\right.\right.$ rank $\left.^{0.5}\right)+\left(\right.$ coefficient $\left.\left._{1} * \mathbf{c w}\right)\right)$

where rank is the abbreviation for the phenotypical trait rank at finish; coefficient is $_{\mathbf{1}}$ the most frequent estimated coefficient using random regression model of square root of rank at finish on carried weights over all individual animals; $\mathbf{c w}$ is the abbreviation for carried weights ranging from 47 to $74.5 \mathrm{~kg}$. New rank at finish showed a minimum of 3.25 and a maximum of 7.60 .

The second equation represents the creation of the trait new distance to first rank.

New distance to first rank $=\left(\left(10-\right.\right.$ distance $\left.^{0.5}\right)+\left(\right.$ coefficient $\left.\left._{2} * \mathrm{cw}\right)\right)$

where distance is the abbreviation for the phenotypical trait distance to first rank; coefficient $_{2}$ is the most frequent evaluated coefficient within random regression model of square root of distance to first rank on carried weights over all animals; $\mathbf{c w}$ is the 
abbreviation for carried weights ranging again from 47 to $74.5 \mathrm{~kg}$. New distance to first rank represented a minimum of 7.29 and a maximum of 19.62 .

Coefficients within random regression model of transformed rank at finish or of transformed distance to first rank on carried weights were also estimated by using two distinct data sets which included observations of two different sex classes (first data set considered only stallions and geldings; the second data set contained only mares). Coefficients using random regression model estimated for these different sex classes, were analysed concerning statistical significance.

\section{$2.2 \quad$ Estimation of genetic parameters}

The data set for evaluation of variance components consisted of 35,776 individual race performances from 3,138 thoroughbreds, which started in flat races in the years 2002 and 2003. The data set involved 4,405 flat races from 47 different race tracks. Pedigree back to the fourth generation was considered (11,446 animals). Only thoroughbreds with more than 4 observations, races with more than 4 starters and trainers with more than 4 starts were included in the data set.

The analysed traits were "new rank at finish" created by equation [1], "new distance to first rank” constructed by equation [2], "square root of rank at finish”, "square root of distance to first rank" and "earnings per race". A log transformation was used for the trait earnings, in order to achieve a reasonable approximation to the normal distribution. Zero earnings were treated as missing values. Table 1 represents the means with standard deviations of these traits.

Table 1

Means $(\bar{x})$, standard deviations (s) and variation coefficients (CV) for racing performances (Mittelwerte $(\bar{x})$, Standardabweichungen (s) und Variationskoeffizienten (CV) für Rennleistungen)

\begin{tabular}{lcccc}
\hline Trait & $\mathrm{N}$ & $\bar{x}$ & $\mathrm{~s}$ & $\mathrm{CV}(\%)$ \\
\hline Square root of rank at finish & 35,776 & 2.77 & 0.73 & 26 \\
New rank at finish & 35,776 & 5.54 & 0.76 & 14 \\
Square root of distance to first rank & 35,776 & 7.26 & 1.80 & 25 \\
New distance to first rank & 35,776 & 14.61 & 1.88 & 13 \\
Log of earnings & 16,110 & 6.82 & 1.15 & 17 \\
Carried weight & 35,776 & 56.50 & 3.35 & 6 \\
\hline
\end{tabular}

The variance components were evaluated using REML procedure as implemented in the program VCE5 (KOVAC et al., 2002). The following univariate genetic-statistical model was utilised for the trait new rank at finish created by equation [1] as well as for the trait new distance to first rank constructed by equation [2].

$\mathbf{y}_{1}=\mathbf{X}_{1} \mathbf{b}_{1}+\mathbf{Z}_{1} \mathbf{a}+\mathbf{Z}_{2} \mathbf{p e}+\mathbf{e}$

where $\mathbf{y}_{\mathbf{1}}$ is the vector of observations containing the traits of each thoroughbred recorded at each individual race as new rank at finish and new distance to first rank, respectively. Vector $\mathbf{b}_{1}$ represents the fixed effects including the effects of sex (stallion, mare and gelding), age of thoroughbred (age classes of 2, .., 10 and $>10$ year old horses), year-season of race (three months were combined to one season), distance of race (5 classes), trainer $(1, \ldots, 455)$, jockey $(1, \ldots, 551)$ and each individual race $(4,405$ races). The vector a represents the random additive genetic effects and vector pe denotes the permanent environmental effects. The known 
incidence matrices $\mathbf{X}_{1}, \mathbf{Z}_{1}, \mathbf{Z}_{2}$ relate the observations to the corresponding fixed and random effects.

In further genetic analyses, a linear regression of carried weights was considered as fixed effect in the statistical model. Variances for the traits square root of rank at finish and square root of distance to first rank were evaluated by using univariate animal models. The following model was either used for square root of rank at finish or square root of distance to first rank.

$\mathbf{y}_{2}=\mathbf{X}_{2} \mathbf{b}_{2}+\mathbf{Z}_{1} \mathbf{a}+\mathbf{Z}_{2} \mathbf{p e}+\mathbf{e}$

where $\mathbf{y}_{2}$ is the vector of observations including the traits of each thoroughbred recorded at each individual race as (5 - square root of rank at finish) and (10 - square root of distance to first rank), respectively. Vector $\mathbf{b}_{2}$ shows the fixed effects including the effects of sex (stallion, mare and gelding), age of thoroughbred (age classes of 2, $\ldots, 10$ and $>10$ year old horses), year-season of race (three months were combined to one season), distance of race (5 classes), trainer $(1, \ldots, 455)$, jockey $(1, \ldots, 551)$, each individual race (4,405 races) and a linear regression on carried weights. Vector a represents the random additive genetic effects and vector pe is the permanent environmental effect. Vector $\mathbf{e}$ considers the residual effects. $\mathbf{X}_{2}, \mathbf{Z}_{1}, \mathbf{Z}_{2}$ are the known incidence matrices.

Estimation of genetic parameters was finally implemented for the traits new distance to first rank and log of earnings using a multiple trait animal model.

$\mathbf{y}_{3}=\mathbf{X}_{3} \mathbf{b}_{3}+\mathbf{Z}_{1} \mathbf{a}+\mathbf{Z}_{2} \mathbf{p e}+\mathbf{e}$

$\mathbf{y}_{\mathbf{3}}$ is the vector of observations containing the traits of each thoroughbred recorded at each individual race as new distance to first rank and log of earnings. Vector $\mathbf{b}_{3}$ showed the fixed effects including the effects of sex (stallion, mare and gelding), age of thoroughbred (age classes of 2, ..., 10 and $>10$ year old horses), distance of race (5 classes), year-season of race (three months were combined to one season), trainer ( 1 , .., 455), jockey $(1, \ldots, 551)$, each individual race $(1, \ldots, 4405)$ which was only considered for the trait new rank at finish and day of race on different race tracks (1, ..., 702) which was only included in the model for the trait log of earnings. Vector a represents the random additive genetic effect and vector pe denotes the random permanent environmental effect. Vector e refers to the residual effect. The known incidence matrices $\mathbf{X}_{3}, \mathbf{Z}_{\mathbf{1}}$ and $\mathbf{Z}_{2}$ relate the observations to the corresponding fixed and random effects.

\subsection{Comparison of different genetic-statistical models}

For the comparison of the two different genetic-statistical models [3] and [4], breeding values were estimated for the traits new rank at finish, new distance to first rank, square root of rank at finish and square root of distance to first rank using the data described in section 2.2. The breeding values resulting from these genetic estimations, were standardised. The program PEST (GROENEVELD et al., 1990) was applied for estimations of breeding values. The main objective of this section was to analyse the influence of two different considerations of carried weights in the statistical models, on the estimated breeding values. Therefore, differences between standardised breeding values of the traits square root of rank at finish evaluated by model [4] and new rank at finish estimated by model [3] were calculated for each thoroughbred. In 
addition, differences were calculated between standardised breeding values of the traits square root of distance to first rank (model [4]) and new distance to first rank (model [3]) for each horse. The carried weights showed the racing potential of horses in races. In the data set, each horse started at least in four races. For each horse the most frequently carried weight was computed. This most frequently carried weight expressed the estimated racing potential of each thoroughbred. It was assumed that horses carrying mostly high weights, showed mainly good racing performances and that thoroughbreds carrying mostly low weights, represented mainly inferior racing performances.

To assess the accuracy of estimated breeding values by two distinct models [3] and [4], differences between standardised breeding values of individual thoroughbreds were related to the horses' most frequently carried weight. The most frequently carried weight was the base for comparison of standardised breeding values estimated with models [3] and [4]. The most frequently carried weights of animals were divided into eight weight classes ( $\leq 50,>50$ to $53,>53$ to $56,>56$ to $59,>59$ to $62,>62$ to $65,>65$ to $68,>68 \mathrm{~kg}$ ). Differences between standardised breeding values were averaged within each of the eight weight classes.

A further criterion for comparison of genetic models [3] and [4], were horses incorrectly selected by breeding values estimated by model [4]. It was assumed that breeding values estimated by the genetic model [3] were not biased by carried weights. Selections by breeding values for the four traits new rank at finish, new distance to first rank, square root of rank at finish and square root of distance to first rank estimated by models [3] and [4], were performed. A selection intensity of $10 \%$ was used. The ranking of selected animals by breeding values for the trait new rank at finish (model [3]) was compared with the ranking of selected animals by breeding values for the trait square root of rank at finish (model [4]). In addition, the ranking of selected thoroughbreds by breeding values for the trait new distance to first rank (model [3]) was related with the ranking of selected thoroughbreds by breeding values for the trait square root of distance to first rank. Horses incorrectly selected by breeding values estimated with model [4] were measured relatively to the total number of selected horses.

3.

Results and discussion

3.1 Creation of new performance traits independent from carried weights

Creation of new performance traits independent from carried weights was one of the main objectives. Therefore, coefficients of phenotypical performance traits on carried weights were estimated within individual animals using random regression model. In both estimations of coefficients within random regression model, a first order polynomial on carried weights for the animal effect was used. Higher order of polynomials were not significant. Figure 1 shows the distribution of regression coefficients using random regression model for square root of rank at finish on carried weights over all individual animals.

These regression coefficients were nearly normal distributed and independent from the genetic potential of horses due to estimation within horses. The most frequent coefficient with a value of 0.049 represented the population average, and was used for creation of the trait new rank at finish in equation [1]. This new created trait reflected more the real performance potential of horses in races because transformed rank at 
finish was independent from the carried weights. New rank at finish showed nearly a normal distribution. Therefore, this trait represented good statistical properties for estimation of variance components and breeding values. When using the performance trait new rank at finish independent from carried weights, thoroughbreds were treated in the same way in genetic estimation.

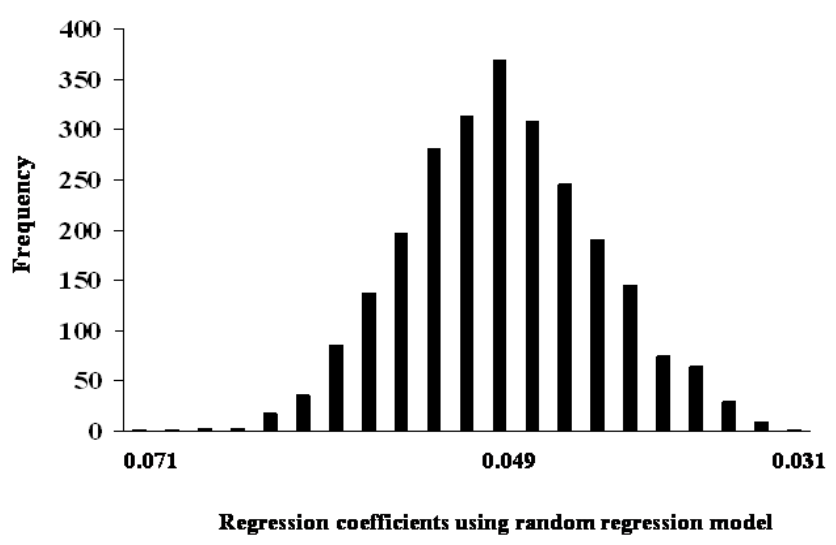

Fig. 1: Distribution of regression coefficients using random regression model of square root of rank at finish on carried weights (Verteilung der Regressionskoeffizienten des getragenen Gewichtes auf die Wurzel der Platzziffer unter Anwendung des Random-Regression-Modells)

Figure 2 shows the distribution of coefficients using random regression model of square root of distance to first rank on carried weights over all individual thoroughbreds.

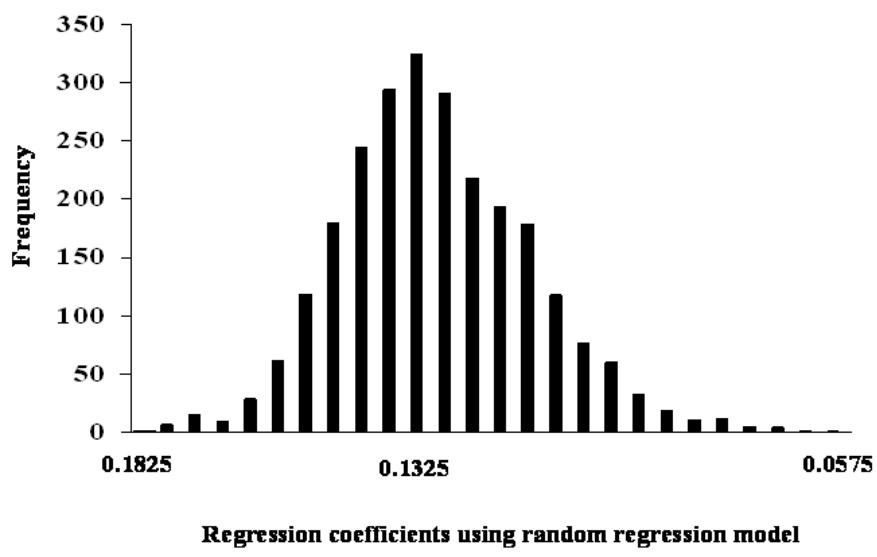

Fig. 2: Distribution of regression coefficients using random regression model of square root of distance to first rank on carried weights (Verteilung der Regressionskoeffizienten des getragenen Gewichtes auf die Wurzel des Abstandes zum ersten Platz unter Anwendung des Random-Regression-Modells)

These coefficients were also nearly normal distributed. The coefficient most frequently estimated for individual thoroughbreds had a value of 0.1325 which was utilised for creation of the performance trait new distance to first rank in equation [2]. This new created trait in equation [2] represented nearly a normal distribution and had therefore good statistical properties for genetic estimation again. New distance to first rank 
reflected also the real racing capacity of horses in races. The thoroughbreds were treated in the same way using this trait in genetic estimation.

In order to test the influence of gender, these coefficients within random regression model of square root of rank at finish on carried weights were also evaluated within individual animals for two distinct data sets including either female or male thoroughbreds. The coefficients most frequently estimated for individual thoroughbreds showed in both data sets a value of 0.049 and were consequently not significant different between genders. Therefore, coefficients of square root of rank at finish on carried weights can be estimated over all sexes.

Coefficients within random regression model of square root of distance to first rank on carried weights were also estimated within individual animals for these two distinct data sets. The most frequent regression coefficient had in both data sets a value of 0.13 and thus no significant difference between genders. Consequently, coefficients of square root of distance to first rank on carried weights can also be estimated over all sexes.

JAITNER et al. (1994) considered a linear regression of carried weights as fixed effect in the genetic-statistical model. When considering a linear regression of carried weights as fixed effect in the statistical models for the traits square root of rank at finish and square root of distance to first rank (as it is shown in model [4]), regression coefficients differ substantially from the above estimated coefficients. Regression coefficients of square root of rank at finish as well as of square root of distance to first rank on carried weights showed values of -0.020 and -0.028 , respectively. These two regression coefficients were not estimated within each animal and thus expected to be biased by the genetic potential of the horses. Therefore, an estimation of coefficients within each animal is expected to be more accurate.

\subsection{Estimation of genetic parameters}

Genetic parameters were first estimated for the traits new rank at finish and new distance to first rank by using the univariate genetic-statistical model [3]. All fixed effects in this genetic model showed a significant influence on the two performance traits. Resulting heritabilities for new rank at finish and also for new distance to first rank are shown in Figure 3. Heritability of new distance to first rank was about $41 \%$ higher than heritability of new rank at finish. Both traits were also estimated together in a multiple trait animal model considering the same fixed effects as in model [3]. Genetic correlation between new rank at finish and new distance to first rank was 1 . So, there is no difference between these two traits. That means, new distance to first rank can be used as a good estimate for new rank at finish with the advantage of showing higher heritability.

Genetic parameters were also estimated for the traits square root of rank at finish and square root of distance to first rank by utilising the univariate genetic-statistical model [4]. The fixed effects in this genetic model represented a significant influence on the two performance traits. The statistical model included a linear regression on carried weights as fixed effect. Figure 3 represents the estimated heritabilities. When considering a linear regression of carried weights as fixed effect in the model, heritabilities for square root of rank at finish and square root of distance to first rank decreased in comparison to heritabilities for new rank at finish and new distance to first rank estimated with model [3]. The fixed effect linear regression on carried 
weights in the genetic model [4], might contain a proportion of the genetic variance. JAITNER et al. (1994) included also a linear regression on carried weights as fixed effect in the animal model and received with 0.15 a much higher heritability for the trait ranking. PREISINGER et al. (1990) found a heritability of 0.07 for the trait ranking, when excluding carried weights from genetic estimation.

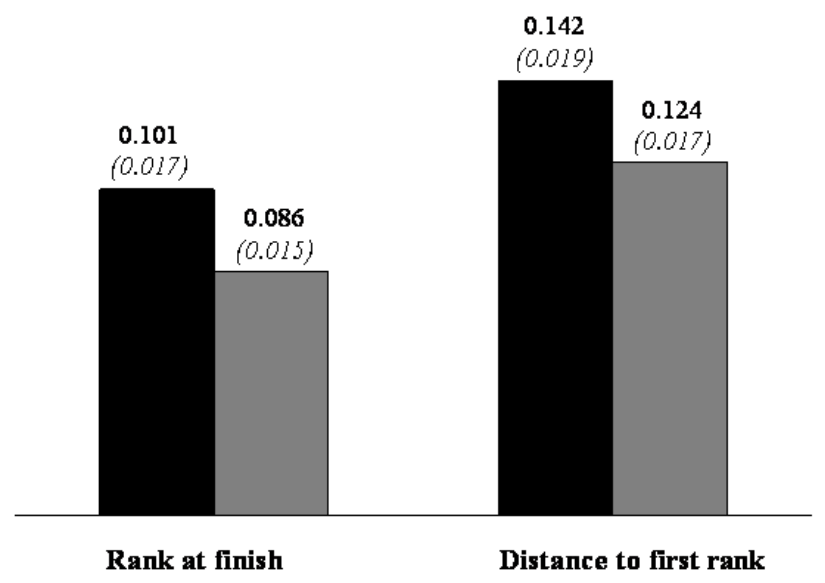

Fig. 3: Heritabilities with standard errors (in parentheses) estimated for two performance traits using two different univariate animal models considering either new created performance trait (dark bar) or a linear regression on carried weights as fixed effect (light bar) (Heritabilitäten mit Standardfehlern (in Klammern) für zwei Leistungsmerkmale geschätzt mit zwei verschiedenen univariaten Tiermodellen, die entweder neu erstellte Leistungsmerkmale (dunkler Balken) oder eine lineare Regression der getragenen Gewichte als fixen Effekt (heller Balken) berücksichtigten)

Estimation of variance components was finally performed for the traits new distance to first rank and log of earnings using a multiple trait animal model. All used fixed effects in model [5] had a significant influence on the two performance traits. Log of earnings was additionally included in the model because of its economical importance. Table 2 shows the heritabilities for the two traits new distance to first rank and log of earnings and the genetic and phenotypic correlations among these traits.

Table 2

Genetic parameters with standard errors (in parentheses) for the two performance traits new distance to first rank and $\log$ of earnings ${ }^{\text {a) }}$ (Genetische Parameter mit Standardfehlern (in Klammern) für die zwei Leistungsmerkmale neuer Abstand zum ersten Platz und log Gewinnsumme ${ }^{\mathrm{a})}$ )

\begin{tabular}{lccc}
\hline Traits & & $(1)$ & $(2)$ \\
\hline New distance to first rank & $(1)$ & $\mathbf{0 . 1 4 5 ( 0 . 0 1 9 )}$ & 0.992 \\
Log of Earnings & $(2)$ & 0.918 & $\mathbf{0 . 0 9 7}(0.014)$ \\
\hline${ }^{a}$ Heritabilities on the diagonal, genetic correlation & above and phenotypic correlation below the diagonal
\end{tabular}

${ }^{a}$ Heritabilities on the diagonal, genetic correlation above and phenotypic correlation below the diagonal.

New distance to first rank represented about 1.5 times higher heritability than the economical trait log of earnings. The trait new distance to first rank was highly genetically and phenotypically correlated with the trait log of earnings and can be used as a good estimate for log of earnings. Therefore, log of earnings are not necessary in the genetic evaluation system because new distance to first rank had much more information due to consideration of all starters.

In German trotter breed is the trait racing time per km very important for selection (ROEHE et al., 2001; BUGISLAUS et al., 2004). It expresses the maximum capacity 
of racing speed for German trotters. Race results of thoroughbreds contain only racing times for the first placed horses in races.

\subsection{Comparison of different genetic-statistical models}

For the comparison of the two different genetic-statistical models [3] and [4] with and without including carried weights directly as fixed effect in the model, differences between standardised breeding values of individual thoroughbreds were related to the horses' most frequently carried weight. Differences were constructed by subtracting standardised breeding values of model [3] from standardised breeding values of model [4]. The weights most frequently carried by thoroughbreds are likely to be a measure for the main racing capacity of horses. Figure 4 shows the development of means of standardised differences with increasing weight classes for the trait rank at finish.

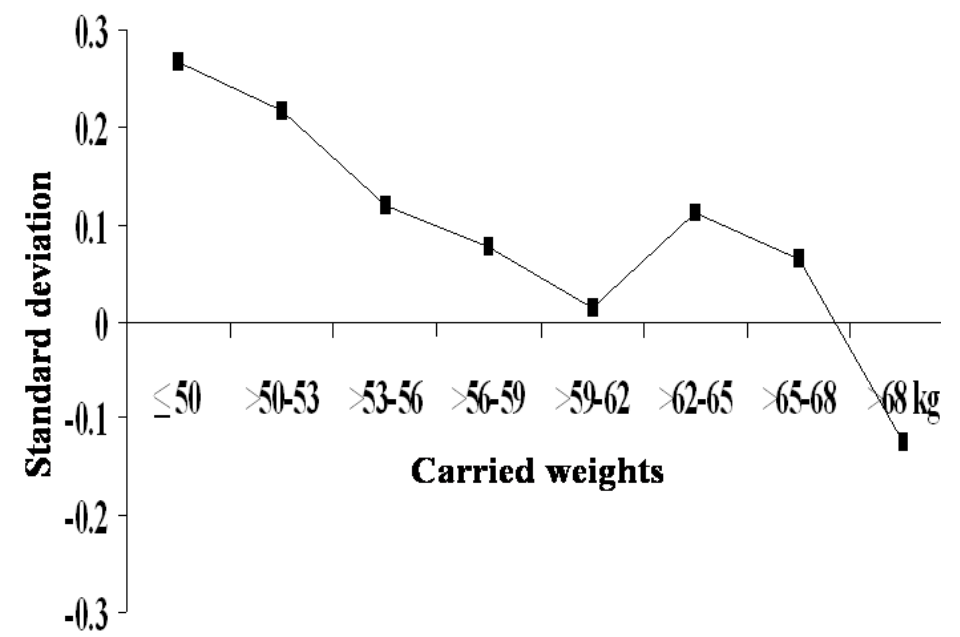

Fig. 4: Means of differences between standardised breeding values using models [3] and [4] for rank at finish over eight weight classes (Mittelwerte der Differenzen zwischen den standardisierten Zuchtwerten für die Platzziffer aus den Modellen [3] und [4] über acht Gewichtsklassen)

The means of standardised differences showed the highest value in the lowest weight class $(\leq 50 \mathrm{~kg})$. That means, standardised breeding values of square root of rank at finish estimated by model [4] were in the lowest weight class on average 0.27 standard deviations larger than standardised breeding values for new rank at finish evaluated by model [3]. The means of standardised differences decreased in the following four weight classes. After a slight increase of differences in the weight classes of ">62 to $65 \mathrm{~kg}$ " and ">65 to $68 \mathrm{~kg}$ ", the standardised difference decreased substantially in the highest weight class (>68 kg). These results show that low performing thoroughbreds associated with low carried weights, were overestimated by the model [4] including a linear regression of carried weights as fixed effect. The differences decreased with increasing weight classes or with increasing racing capacity of horses and were even negative at the highest weight class. This indicates that using model [4] with fixed regression underestimated the horses carrying high weights. Therefore, for the trait rank at finish, genetic estimation by model [3] was recommended.

Figure 5 represents the means of standardised differences dependent of weight classes for the trait distance to first rank. The course of means of differences corresponds nearly to the course of means of standardised differences in Figure 4. Breeding values 
for square root of distance to first rank estimated by model [4] were overestimated for low performing thoroughbreds and underestimated for high performing horses.

Breeding values estimated by model [3] reflected more the real genetic potential of horses.

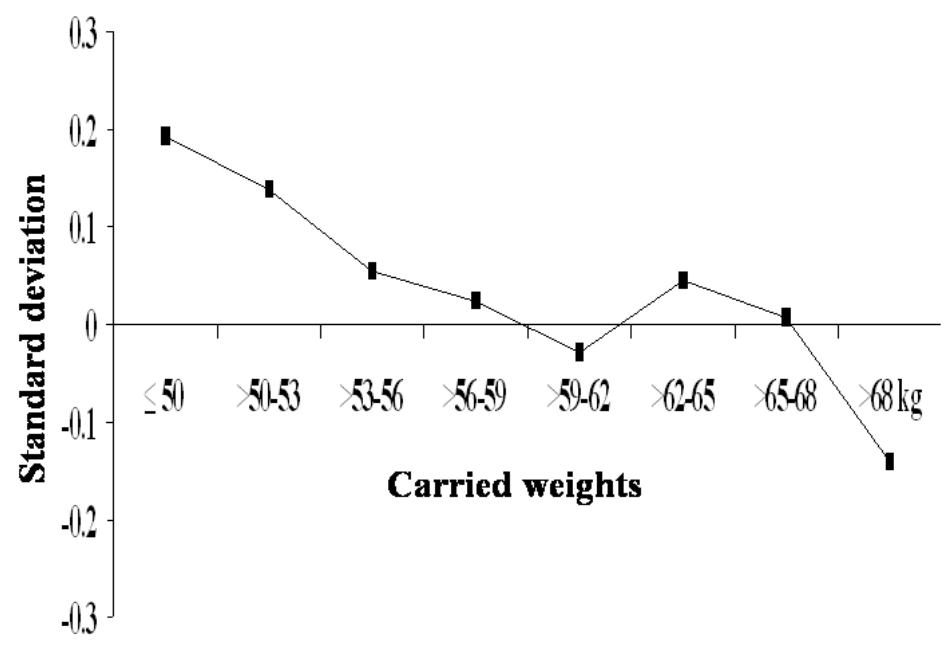

Fig. 5: Means of differences between standardised breeding values using models [3] and [4] for the trait distance to first placed horse in a race over eight weight classes (Mittelwerte der Differenzen zwischen den standardisierten Zuchtwerten des Abstandes zum ersten Platz aus den Modellen [3] und [4] über acht Gewichtsklassen)

A further criterion for comparison of models [3] and [4] was the percentage of thoroughbreds incorrectly selected by breeding values using model [4]. When selecting by breeding values for the trait rank at finish, $6.9 \%$ of thoroughbreds were incorrectly selected by breeding values estimated with the genetic model [4] including a linear regression of carried weights as fixed effect. Selection by breeding values for the trait distance to first rank showed $7.2 \%$ incorrectly selected thoroughbreds when using breeding values evaluated with model [4]. These results showed also that new performance traits using model [3] which were independent from carried weights, were more appropriate for genetic estimation.

\section{Conclusion}

The consideration of new created traits in the statistical model [3] showed a good suitability for genetic estimation. Breeding values estimated by model [3] reflected nearly the tendency of mostly carried weights of horses. Genetic estimation by model [4] resulted in overestimation of breeding values for low performing thoroughbreds and underestimation of breeding values for high performing horses. The genetic correlation between new rank at finish and new distance to first rank was 1 . That means, new distance to first rank can be used as a good estimate for new rank at finish with the advantage of having a substantial higher heritability. New distance to first rank was also highly genetically correlated with log of earnings and can be used as a good estimate for log of earnings. Therefore, log of earnings are not necessary in the genetic estimation because new distance to first rank included much more information due to consideration of all starters. Consequently, a univariate animal model [3] for the trait new distance to first rank was recommended. 
The authors are grateful to the "Direktorium für Vollblutzucht und Rennen e. V." for providing racing performances and pedigree data.

\section{References}

BUGISLAUS, A.-E.; ROEHE, R.; KALM, E.:

Comparison of two different statistical models considering individual races or race tracks for evaluation of German trotters. Livest. Prod. Sci. (2004) (accepted)

GROENEVELD, E.; KOVAC, M.; WANG, T.:

PEST, a general purpose BLUP package for multivariate prediction and estimation. Proc. $4^{\text {th }}$ World Congr. Genet. Appl. Livest. Prod. 13 (1990), 468-475

JAITNER, J.; REINHARDT, F.; PREISINGER, R.:

Estimation of breeding values for Thoroughbreds in Germany. $45^{\text {th }}$ Annual Meeting EAAP, Edinburgh, Scotland (1994)

KOVAC, M.; GROENEVELD, E.; GARCIA-CORTES, L. A.:

VCE5, a package for the estimation of dispersion parameters. Proc. $7^{\text {th }}$ World Congr. Genet. Appl. Livest. Prod. 33 (2002), 741-742

PREISINGER, R.; REINHARDT, F.; KALM, E.; BORMANN, P.:

Selection criteria with regard to estimation of breeding values in Thoroughbred. $41^{\text {st }}$ Annual Meeting EAAP, Toulouse, France (1990)

PREISINGER, R.; REINHARDT, F.; KALM, E.:

Neue Perspektiven für die Zuchtwertschätzung Rennleistung. Vollblut 136 (1993), 276-279

ROEHE, R.; SAVAS, T.; BRKA, M.; WILLMS, F.; KALM, E.:

Multiple-trait genetic analyses of racing performances of German trotters with disentanglement of genetic and driver effects. Arch. Tierz., Dummerstorf 44 (2001), 579-587

SCHULZE-SCHLEPPINGHOFF, W.; CLAUS, J.; KALM. E.:

Die Erstellung eines BLUP-Zuchtwertschätzmodells für die deutsche Vollblutzucht. Züchtungskunde 59 (1987), 25-30

UPHAUS, H.; SCHMUTZ, M.:

Zuchtwertschätzung für Rennleistung. 2. Pferde-Workshop in Uelzen (1998), 71-77

Received: 2004-08-27

Accepted: 2004-09-20

Authors' addresses

Dipl.-Ing. agr. ANTKE-ELSABE BUGISLAUS*, Prof. Dr. RAINER ROEHE,

Prof. Dr. Dr. h.c. mult. ERNST KALM

Christian-Albrechts-University of Kiel

Institute of Animal Breeding and Husbandry

Olshausenstr. 40

D-24098 Kiel

Germany

Dr. HUBERT UPHAUS

Direktorium für Vollblutzucht und Rennen e. V.

Rennbahnstr. 154

D-50737 Köln

Germany

*Corresponding author

Dipl.-Ing. agr. ANTKE-ELSABE BUGISLAUS

Institut für Nutztierwissenschaften und Technologie

Universität Rostock

Justus-von-Liebig-Weg 8

D-18059 Rostock

Germany

E-Mail: antke-elsabe.bugislaus@auf.uni-rostock.de 